\title{
Influence of complex geometries on the properties of laser-hardened surfaces
}

\author{
Joerg Volpp ${ }^{1}$ (I) $\cdot$ Handika Sandra Dewi ${ }^{1} \cdot$ Andreas Fischer $^{2} \cdot$ Thomas Niendorf $^{2}$
}

Received: 14 January 2020 / Accepted: 13 April 2020 / Published online: 25 April 2020

(C) The Author(s) 2020

\begin{abstract}
Laser surface hardening provides for many advantages in terms of flexible production due to very localized and controlled energy input into the material. Laser processing offers the possibility to treat surfaces in order to locally strengthen the areas that are prone to fatigue cracking. It is well known that laser energy absorption depends on many parameters, e.g., the surface structure and the surface orientation. The incident angle of the laser beam plays a key role in this regard. When complex geometries like crankshaft fillets are treated, the surface cannot be considered a series of flat surfaces. Obviously, this leads to locally varying degrees of energy absorption. In the present work, curved surface structures were chosen in order to analyze the impact of the geometrical characteristics on surface and subsurface material properties after laser treatment. Microstructure evolution generally was found to be similar for flat and curved geometries. However, even if higher absorption in the groove due to the illumination at larger incident angles was expected, the outer parts of the curved geometry were not fully hardened. Thus, the increased effective length of the complex geometry-treated and the larger heat-affected volume are expected to have a more dominant influence on the final appearance of the subsurface microstructure. Eventually, for austenitization of the complete illuminated surface volume, the energy density needs to be increased.
\end{abstract}

Keywords Laser surface hardening $\cdot$ Microstructure $\cdot$ Residual stress $\cdot$ Microalloyed steel

\section{Introduction}

Laser beam processing is widely used in many fields and for many applications today. Besides well-known applications, e.g., welding, cutting, and drilling, where the material is heated to temperatures above the melting point, several processes are in operation, where the melting temperature is not reached, e.g., in laser hardening. In these cases, only solid to solid phase transformations induce changes of mechanical properties [1]. During laser hardening, the temperature increase in the surface region can be considered to be extremely rapid [2] compared with conventional hardening methods like induction heating [3]. Since the base material around the laser-illuminated area

Joerg Volpp

Jorg.volpp@1tu.se

1 Department of Engineering Sciences and Mathematics, Luleå University of Technology, 97187 Luleå, Sweden

2 Institute of Materials Engineering, Metallic Materials, University of Kassel, 34125 Kassel, Germany acts as an effective heat sink, rapid cooling occurs (e.g., [1]). In general, the transformation of the material from austenite to martensite (e.g., [4]) and the precipitation effects (e.g., [5, 6]) can lead to surface hardening. The use of a laser beam as a heat source in order to illuminate the surface provides the advantage of a controlled and local heat input. However, the depths of the hardened zone is mostly comparably narrow due to the limited dwell time, which might not give enough time for microstructural transformations in deeper regions (e.g., [7]). It was shown that the fast thermal cycle leads to a different microstructural appearance compared with traditional heat treatments due to the limited time for carbon diffusion (e.g., [8]) inherent to the rapid laser processes. In consequence, ferrite islands can be present although austenitization temperature was reached at the surface and in subsurface areas [7].

One of the possible applications of laser hardening is seen in crankshaft hardening, e.g., treatment of the fillet regions, where currently traditional surface treatments (e.g., induction heating, deep rolling) are used in order to prevent fatigue cracking. Typically, microalloyed steels are used for crankshafts, such as $38 \mathrm{MnSiVS5}$ [9-12] and 44MnSiVS6 [4], respectively. 
Fig. 1 Principle setup used for laser beam hardening of a flat and b curved surfaces

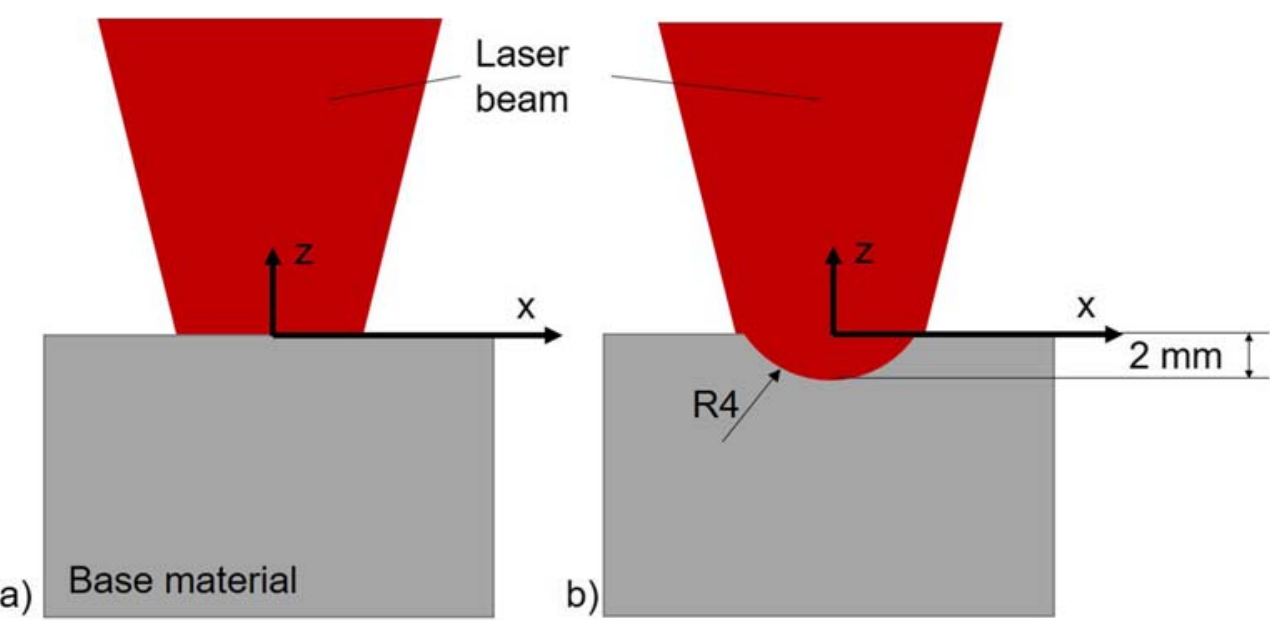

The fillet region of a crankshaft shows a quite complex geometry, which is curved in two ways and is typically polished, which can decrease the laser beam energy absorption [13]. Typically, the laser beam illuminates a flat surface for which the absorption values are known in general (e.g., [14]). However, the laser energy absorption depends also on the local incident angle (e.g., [14]). This effect needs to be considered in order to establish a reliable procedure for crankshaft hardening using the laser beam.

Eventually, the impact of complex geometrical conditions, e.g., related to crankshaft fillets, on laser hardening effectiveness and robustness must be understood in detail in order to identify strategies for safe and reliable treatments.

\section{Methodology}

\subsection{Setup and materials}

In order to investigate the impact of the surface geometries on the characteristics of the heat-affected and hardened zones, laser hardening experiments were conducted in the present work using a laser beam emitted by an IPG fiber laser (max. power of $15 \mathrm{~kW}$ ) at a laser power of $2 \mathrm{~kW}$ and a round top-hat beam shape of $9 \mathrm{~mm}$ diameter. The focal position was placed at the material surface at $z=0$ (Fig. 1). The feeding rate was $10 \mathrm{~mm} / \mathrm{s}$. No shielding gas was used. A microalloyed medium carbon steel $38 \mathrm{MnSiVS5}$ was investigated (Table 1). The average surface roughness of the polished surfaces was 0.5 to $1 \mu \mathrm{m}$.

Two surface geometries were studied to compare flat and curved specimens (Fig. 1). Four specimens of both the curved and flat specimens were produced. The milled groove simulates a geometry similar to the fillet section of a crankshaft. The radius of the groove of $4 \mathrm{~mm}$ at a depth of $2 \mathrm{~mm}$ results in a groove width of $6.9 \mathrm{~mm}$ at the material surface.
The hardened surface regions were characterized on specimen cross sections with respect to microstructure and micro-hardness using optical microscopy and Vicker hardness tests, respectively. Residual stresses and the integral width values were determined using X-ray measurements transverse ( $\mathrm{x}$ ) and longitudinal (y) to the laser feeding direction. For details regarding characterization, the reader is referred to previously published work on the topic [15].

\subsection{Absorption calculation}

The laser beam incident angle relative to the illuminated material surface influences the local energy absorption. The angle-dependent absorption coefficients applied in the present work were extracted from [14] (Fig. 2).

The angles of incidence were calculated based on the shape of the groove in 20 steps, and the related absorption coefficient was determined (Fig. 3).

The absorption coefficients were then used as input for the calculation of the locally absorbed energy. The absorbed energy was calculated for flat and curved surfaces, while the absorption coefficient for the flat surface was considered to be constant at a value of 0.31 .

A circular top-hat beam profile was employed in the present work. The total energy input along a specific evaluation line (Fig. 4) was calculated.

The total energy input was accumulated based on steps of $0.35 \mathrm{~mm}$ size. Since a top-hat beam was used, the intensity (power per illuminated area) is assumed to

Table 1 Nominal chemical composition of 38MnSiVS5 (wt\%, balance iron)

\begin{tabular}{llllllll}
\hline $\mathrm{C}$ & $\mathrm{Mn}$ & $\mathrm{Si}$ & $\mathrm{V}$ & $\mathrm{Cr}$ & $\mathrm{Ni}$ & $\mathrm{S}$ & $\mathrm{Mo}$ \\
\hline 0.38 & 1.4 & 0.61 & 0.11 & 0.13 & 0.09 & 0.061 & 0.03 \\
\hline
\end{tabular}




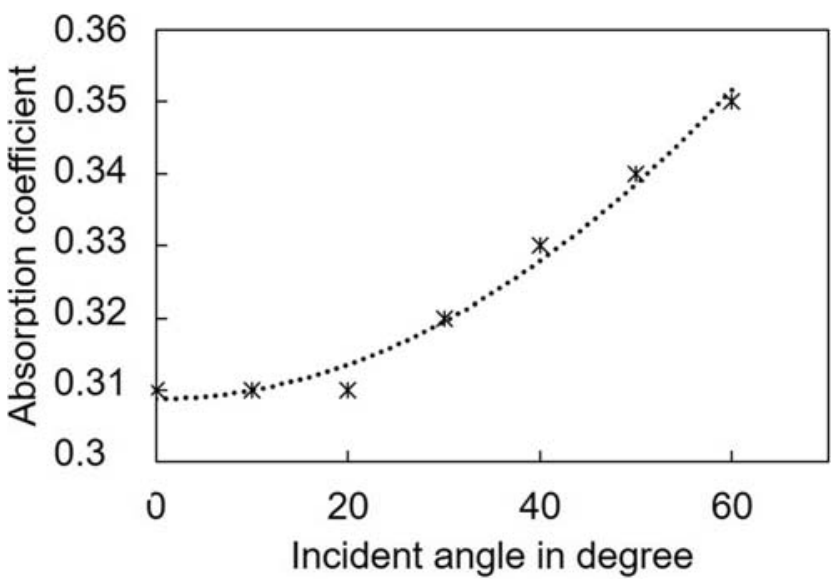

Fig. 2 Angle-dependent absorption coefficients according to [14]

be constant across the entire beam. The input energy was calculated to

$E=A \cdot I \cdot N_{s e c} \cdot l / v_{s}$

based on [16] and summed up for all time steps of laser beam-surface interaction. In Eq. (1) the input energy $E$, the absorption coefficient $A$, the local laser intensity $I$, the number of sectors $N_{\text {sec }}$ to sum up along the length $l$ of the laser beam at that position and $v_{s}$ the processing velocity are considered.

\section{Results}

\subsection{Energy distribution on the surfaces}

The calculation of the energy absorption along a single, representative evaluation line during beam illumination was conducted for a flat and a curved surface (Fig. 5).

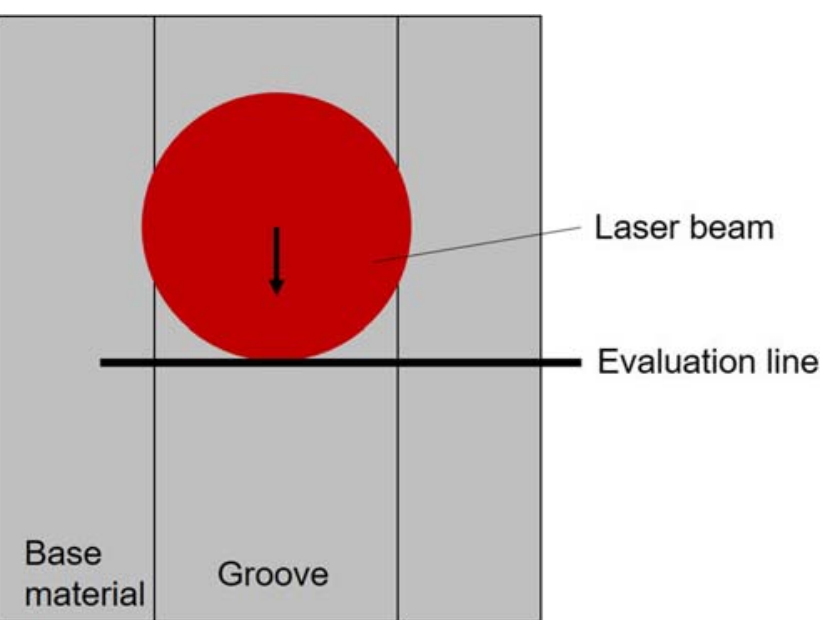

Fig. 4 The evaluation line being the basis for energy absorption calculation

Due to the higher absorption coefficients at a given beam incidence, e.g., for any angles deviating from zero, the absorbed energy is slightly higher at curved surfaces.

\subsection{Macrostructure and hardness}

The macrostructures and hardness values were evaluated within representative cross sections of flat and curved specimens upon laser treatment (Fig. 6).

The hardened zones can be identified in the cross sections due to the different optical appearance of the martensitic regions compared with the base material. In parallel, the hardness values reveal the transition from the hardened to the nonhardened regions. Obviously, both characterization techniques qualitatively reveal the same distinct features. The depths determined from the optical micrographs and the hardness maps are highlighted in Table 2.
Fig. 3 Absolute angles and related absorption coefficients in the groove
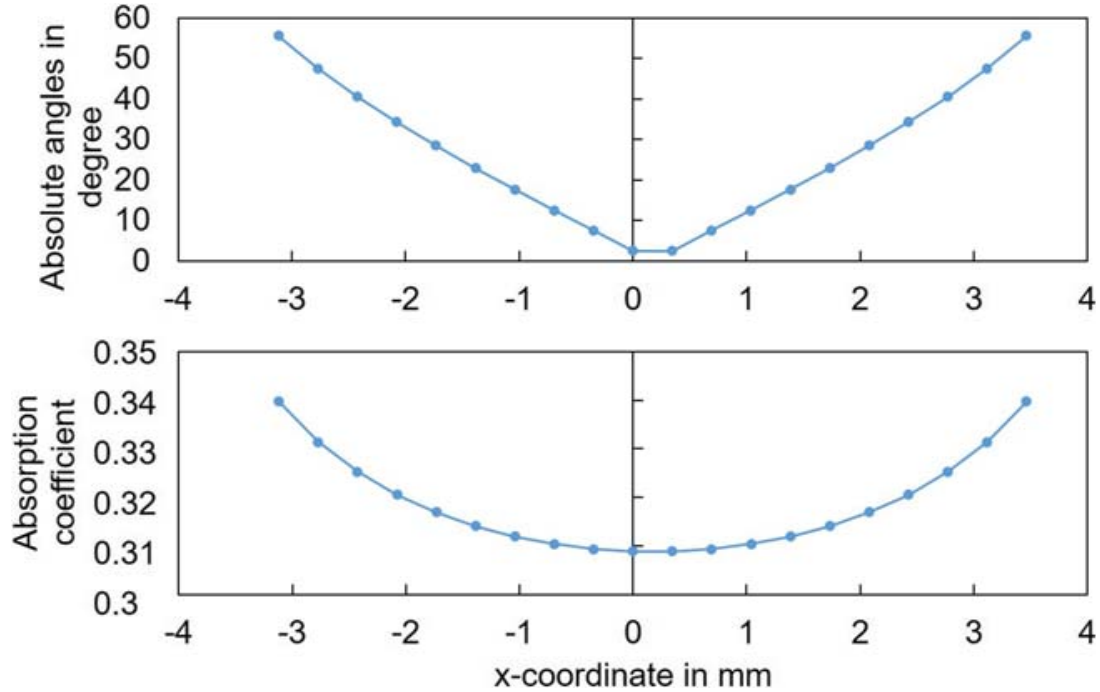


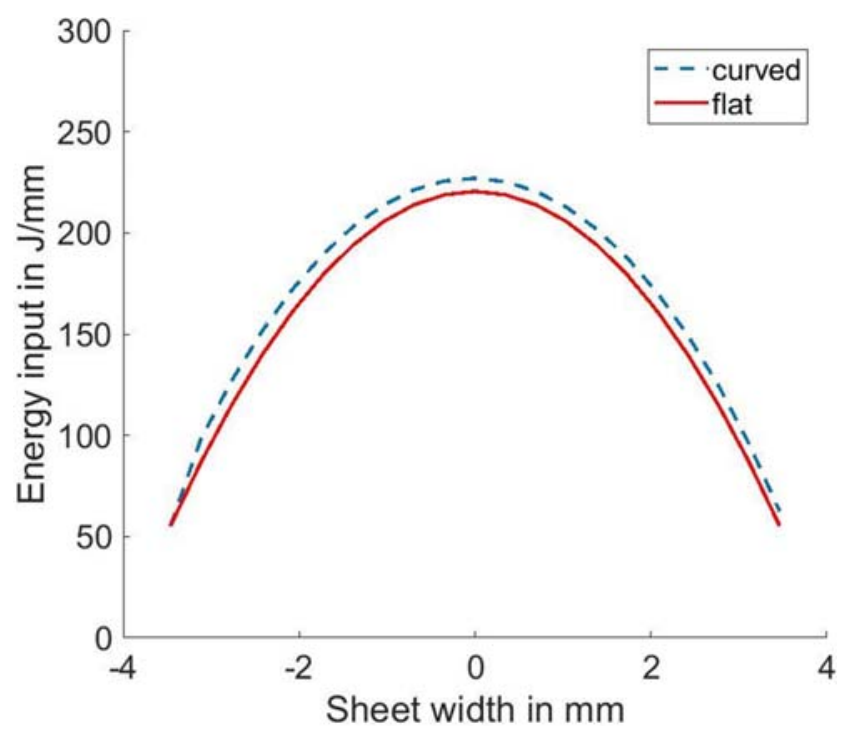

Fig. 5 Distribution of the local energy input for the flat and curved surfaces

The maximum hardness values measured were 942 HV0.05 (flat surface) and 943 HV0.05 (curved surfaces). The variations within the hardness maps shown in Fig. 6 reveal very similar patterns for flat and curved surfaces.
Table 2 Maximum depths of the laser hardened zones for flat and curved surfaces including sample standard deviations

\begin{tabular}{lll}
\hline Max. depth & Optical microscopy & Hardness maps \\
\hline Flat & $890 \mu \mathrm{m} \pm 6.5 \mu \mathrm{m}$ & $897 \mu \mathrm{m} \pm 4 \mu \mathrm{m}$ \\
Curved & $719 \mu \mathrm{m} \pm 75 \mu \mathrm{m}$ & $706 \mu \mathrm{m} \pm 17 \mu \mathrm{m}$ \\
\hline
\end{tabular}

\subsection{Residual stress analysis}

The X-ray measurements conducted in the middle of the groove revealed in-depth information on both residual stress and the integral widths (Fig. 7).

The residual stress values are characterized by pronounced scatter within the hardened zones. This is in line with previous studies on a similar steel grade. Due to the extremely rapid nature of laser treatment, the material is not fully austenitized, and ferrite islands remain due to the limited time for carbon diffusion [7]. In case of the present work, the absolute values are similar for both surface geometries. However, the transition zones, e.g., the areas, in which the compressive stresses turn into tensile stresses, seem to be slightly different. The transition of compressive to tensile residual stresses appears smoother for the flat specimens compared with the curved ones. In addition, the maximum depths of compressive residual stresses of $899 \mu \mathrm{m} \pm 24 \mu \mathrm{m}$ (flat) and $776 \mu \mathrm{m} \pm 5 \mu \mathrm{m}$

Fig. 6 Microstructure analysis by optical microscopy of the hardened region (top) and hardness distribution (bottom) for flat and curved surfaces
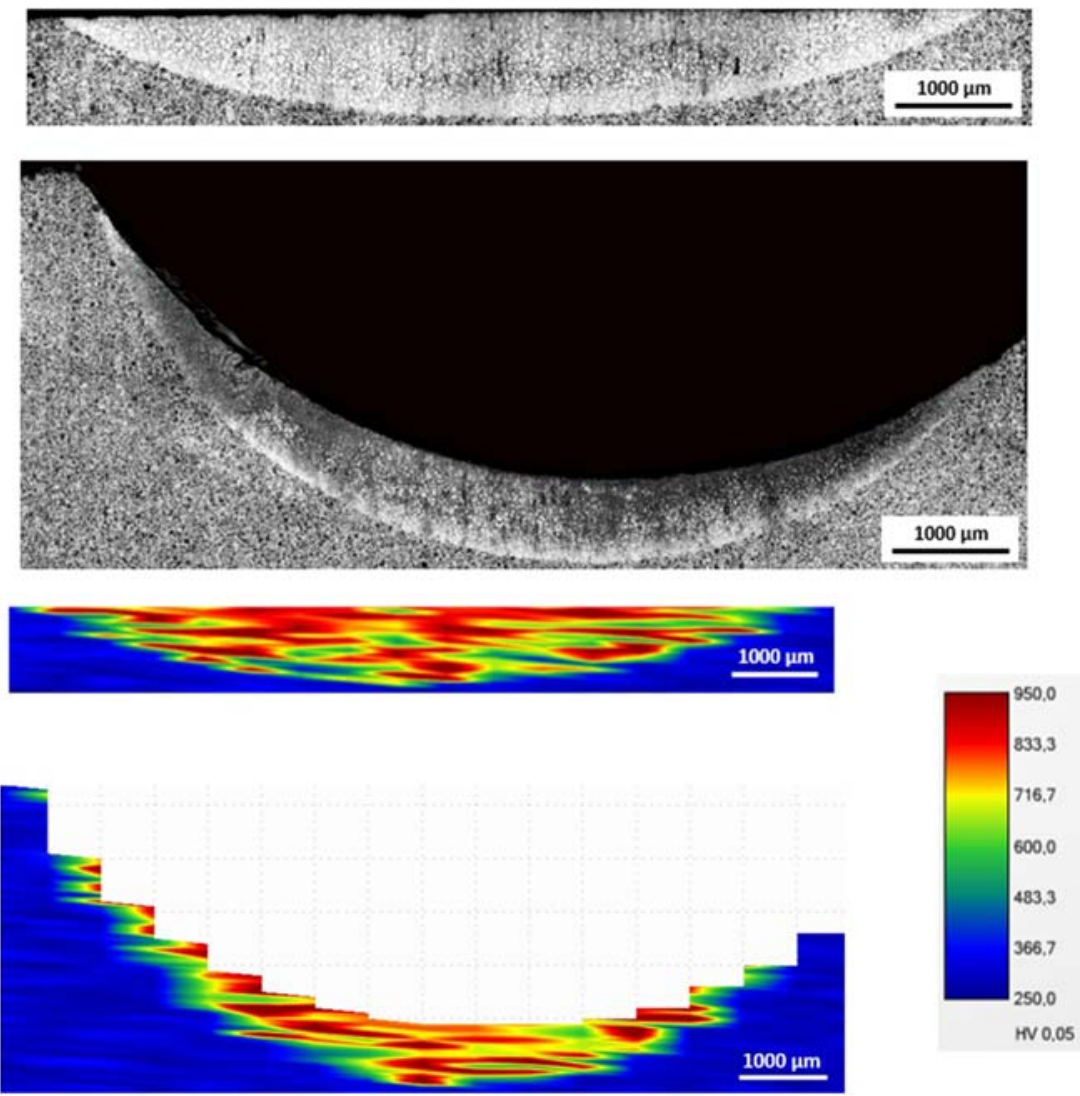

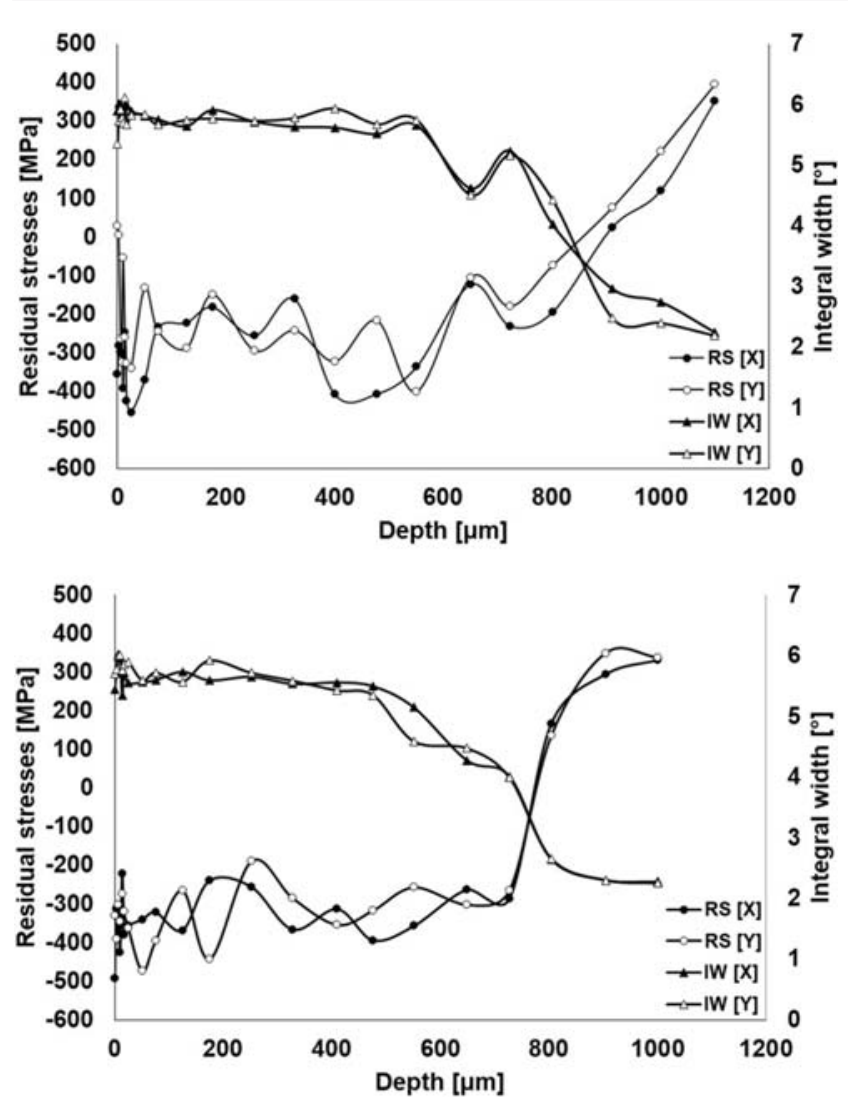

Fig. 7 Residual stress and integral width profiles (along the center of the hardened zone/center of the groove) for laser-hardened flat (top) and curved (bottom) surfaces

(curved) differ for both specimen types. Integral width values in both cases support the findings related to residual stress and hardness.

\section{Discussion}

In the "Results" section, it is shown that the laser-hardened zones of the flat and the curved specimen geometries are in general very similar. By optical microscopy, hardness measurements and X-Ray analysis, it was revealed that surface layers are characterized by very similar characteristics and dimensions when the cross-sectional view is considered (Figs. 6 and 7, Table 2). The heat-affected zones were determined based on the presence of martensite (optical microscopy), hardness maps, residual stress measurements, and integral width profiles. This clearly indicates that for identification of the depths of the hardened zones, either method can be used. Since very similar maximum hardness values were seen for curved and flat surfaces, it can be concluded that there is no significant impact of the surface shape on the overall microstructure evolution and phase transformation mechanisms, upon laser processing.
Although a top-hat beam was used, the energy input differs within the hardened zone (Fig. 5). In the center of the lasertreated surface, most energy is absorbed resulting in highest hardened depths. This was seen in the center of the hardened tracks for both surface shapes. The slightly higher absorption values at the curved surface (Fig. 5) did not result in a higher hardened depth as initially expected. Since surface preparation, and thus, the surface roughness was similar for the flat and curved surfaces, and as the processing conditions were the same for both conditions, other factors must be responsible for the discrepancy. One impact factor can be the laser beam focal position. As the curved surface is characterized by an absolute depth (specimen surface to lowest point in the groove) of $2 \mathrm{~mm}$ (Fig. 1), laser energy is delivered at different focal planes along the groove. As the focal position was the same as in case of the flat specimen, the intensity values in the center can be lower than on the flat surface. Therefore, the effective intensity of the laser beam is reduced as the laser has to heat up a larger surface, and thus, a larger specimen volume in case of the curved geometry. As the laser power was kept constant throughout the present study, this most dominant influencing factor led to an incomplete austenitization of the outer areas of the groove and a decrease of depth of the heat-affected zone in general.

While the absolute hardness values within the direct vicinity of the surface and the residual stress values are similar in case of the flat and curved surfaces, a smoother transition of the residual stresses for the flat surface was found. As already discussed before, the complex geometry of the groove does not only result in an enlarged surface area, which is illuminated by the laser beam, but also leads to an enlarged volume of the underlying base material. In fact, this leads to a strongly promoted heat dissipation, so that only a smaller sub-surface area is austenitized. Thus, martensitic transformation is limited to smaller specimen volumes leading to the changes in residual stress and hardness profiles as revealed by the results presented in the present work (Fig. 6). Since the residual stress development during laser hardening mainly depends on the martensitic transformation and the corresponding temperature gradient, a more pronounced influence of the bulk material as the heat sink compared with the flat surface can be derived from the present results for the curved specimen condition. This effect can be also seen by comparing the transition zones of the different geometries in Fig. 7. For the complex geometry, an abrupt transition of the corresponding residual stress state can be observed.

\subsection{Conclusions}

The results of the present work focusing on the impact of different surfaces treated by a laser beam to induce hardening revealed: 
The depth of a hardened zone can be measured in cross sections, hardness distributions, or residual stress curves since comparable values were identified.

No significant impact of the surface shape on the microstructural development characteristics could be identified, which means that the assumption of a significant impact of the angle-dependent laser beam absorption was not seen in this case.

The defocusing of the laser beam in the groove along with the locally reduced laser beam intensity seems to lead to a wider heat input that decreases the effect of the expected higher absorption in a groove due to the illumination at larger incident angles.

The enlarged laser illuminated area results in an enlarged underlying volume of the base material, which promotes the self-quenching process and thus leads to an increased thermal influence. This results in a less material transformed into austenite and martensite in the edge regions of the hardened zone, which also affects the residual stress states.

Acknowledgments The authors gratefully acknowledge funding from the EC Research Fund for Coal and Steel, RFCS, for the project Stiffcrank, no. 754155 .

Funding Information Open access funding provided by Lulea University of Technology.

Open Access This article is licensed under a Creative Commons Attribution 4.0 International License, which permits use, sharing, adaptation, distribution and reproduction in any medium or format, as long as you give appropriate credit to the original author(s) and the source, provide a link to the Creative Commons licence, and indicate if changes were made. The images or other third party material in this article are included in the article's Creative Commons licence, unless indicated otherwise in a credit line to the material. If material is not included in the article's Creative Commons licence and your intended use is not permitted by statutory regulation or exceeds the permitted use, you will need to obtain permission directly from the copyright holder. To view a copy of this licence, visit http://creativecommons.org/licenses/by/4.0/.

\section{References}

1. Schaaf P (2010) Laser processing of materials. Springer, Verlag. https://doi.org/10.1007/978-3-642-13281-0
2. Gladush GG, Smurov I (2011) Mechanisms of laser processing of metal surfaces. In: physics of laser materials processing: theory and experiment. Springer-Verlag. pp. 45-143

3. Grum J (2006) Residual stress and fatigue strength after transformation hardening and various strain hardening. Int $\mathrm{J}$ Microstruct Mater Prop 1:161-182. https://doi.org/10.1504/IJMMP.2006. 010624

4. Bhadeshia H, Honeycombe R (2006) Steels: microstructure and properties. Butterworth-Heinemann. https://doi.org/10.1016/B9780-7506-8084-4.X5000-6

5. He K, Edmonds DV (2002) Formation of acicular ferrite and influence of vanadium alloying. Mater Sci Technol 18:289-296. https:// doi.org/10.1179/026708301225000743

6. Dewi HS, Volpp J, Kaplan AFH (2020) Short thermal cycle treatment with laser of vanadium microalloyed steels. In: Journal of Materials Processing Technology (in review)

7. Dewi HS, Fischer A, Volpp J, Niendorf T, Kaplan AF (2020) Microstructure and mechanical properties of laser surface treated 44MnSiVS6 microalloyed steel. Opt Laser Technol 127:106139

8. Su B, Ma Q, Han Z (2017) Modeling of austenite decomposition during continuous cooling process in heat treatment of hypoeutectoid steel with cellular automaton method. Steel Res Int 88:12. https://doi.org/10.1002/srin.201600490

9. Dini G, Vaghefi MM, Shafyei A (2006) The influence of reheating temperature and direct-cooling rate after forging on microstructure and mechanical properties of V-microalloyed steel 38MnSiVS5. ISIJ Int 46:89-92

10. Medina SF, Chapa M (2006) Ti / AI interaction and austenite grain control in crankshaft manufacturing with $38 \mathrm{MnSiVS5}$ steel, steels automot. Apl. 77:712-719. https://doi.org/10.1002/srin.200606452

11. Singh P, Batra U, Sangal S (2017) Fracture toughness behavior of $38 \mathrm{MnSiVS} 5$ microalloyed steel after isothermal transformation and thermomechanical processing. Mater Today: Proc 4:8528-8537. https://doi.org/10.1016/j.matpr.2017.07.199

12. Equbal I, Equbal A, Mukerjee D (2018) A full factorial designbased desirability function approach for optimization of hot forged vanadium micro-alloyed steel. Metallogr Microstruct Anal 7:504 523. https://doi.org/10.1007/s13632-018-0473-y

13. Dewi HS, Volpp J, Kaplan AFH (2019) Laser beam absorption depending on the angle of incidence on ground surfaces. In: Proceeding of WLT Lasers in Manufacturing Conference 2019, Munich, Germany

14. Dausinger F, Shen J (2008) Energy coupling efficiency in laser surface treatment. ISIJ Int 33:925-933

15. Fischer A, Scholtes B, Niendorf T (2019) A screening approach for qualitative evaluation of residual stress states -application to laser hardened microalloyed steel. HTM 74(2019):151-163

16. Fischer A, Dewi HS, Volpp J, Tranchero JO, Otero JLA, Grela JS, Krooss P, Kaplan AFH, Niendorf T (2020) Mathematical screening approach of laser-induced compressive residual stress profiles (in preparation)

Publisher's note Springer Nature remains neutral with regard to jurisdictional claims in published maps and institutional affiliations. 